Article

\title{
Synthesis of Ethylene Glycol Dimethacrylate-Methyl Methacrylate Copolymers, Determination of their Reactivity Ratios, and a Study of Dopant and Temperature Effects on their Conductivities
}

\author{
Ulku S. Ramelow * and Sreedhar Pingili \\ Department of Chemistry, McNeese State University, Lake Charles, LA 70609-0455, USA; \\ E-Mail: omsreedhar@gmail.com
}

* Author to whom correspondence should be addressed; E-Mail: uramelow@mcneese.edu; Tel.: 001-337-475-5775; Fax: 001-337-475-5950.

Received: 26 July 2010; in revised form: 24 August 2010 / Accepted: 25 August 2010 /

Published: 26 August 2010

\begin{abstract}
Ultraviolet radiation was used as a photochemical initiator to synthesize ethylene glycol dimethacrylate-methyl methacrylate copolymers. Infrared spectroscopy was used to calculate reactivity ratios and to identify the type of copolymerization. The reactivity ratios of EGDMA and MMA were calculated as 0.6993 and 1.8635, respectively. The effect of lithium perchlorate as a dopant on copolymer conductivity and conversion was studied. The addition of dopant increased the conductivity of copolymers. For copolymers containing 5\% MMA in the feed, dopant increased conductivity about 775 times; when the MMA percentage was $20 \%$ in the feed, dopant increased conductivity about 100 times. As MMA percentage increases in the copolymer, the conductivity values decrease from the $\mathrm{mS}$ to the $\mu \mathrm{S}$ region. This is consistent with the fact that PMMA has a lower conductivity than PEGDMA. The conductivity change of homopolymers and copolymers at various temperatures were studied. Both MMA and EGDMA polymers and their copolymers show a minimum in their conductivity $v s$. temperature graphs, indicating that they first act as a conductor and after a minimum temperature, become semiconductors and can be used to control current in electrical devices by temperature change. The measurement of conductivity change with time provided a new way to follow the kinetics of polymer/dopant reactions. The activation energy of interaction with dopant was calculated as $31.52 \mathrm{~kJ} / \mathrm{mol}$ for MMA/EGDMA copolymers; for PEGDMA alone it was $54.7 \mathrm{~kJ} / \mathrm{mol}$.
\end{abstract}


Keywords: conductivity; dopant; copolymer; reactivity ratio

\section{Introduction}

Conductive polymers are organic polymer semiconductors. Conductive polymers have extended delocalized bonds that create a bond structure similar to silicon. Delocalization can be accomplished by forming a conjugated backbone of continuous overlapping orbitals, for example, alternating single or double carbon-carbon bonds, which leaves a continuous path of overlapping $p$ orbitals. This creates degeneracy in the molecular orbitals which leads to the filled (electron containing) and unfilled (valence and conductive) bands, respectively, that defines a semiconductor [1]. It is not until an electron is removed from the valence band (p doping) or added to the conduction band (n doping) does a conducting polymer become highly conductive [1].

McGinness, Corry and Proctor reported a high conductivity state in polyacetylene, and the first organic electric device. This was a high voltage controlled switch [2]. The 2000 Nobel Prize in chemistry was awarded for the discovery and the study of conductive polymers to the three inventors of conducting polymers. Their subsequent research has lead to the formation of some patents and polymer diodes.

The biggest advantage of conductive polymers is processibility. Some conductive polymers are plastics and can combine the mechanical properties (flexibility, toughness, elasticity, etc.) of plastics with high electrical conductivities of a doped conjugated polymer [1]. Among conductive plastics polyaniline stands out due to its properties [3]. In 2000 by using polyaniline compounds, Philips fabricated an all-polymer integrated circuit with 326 transistors and more than 300 handed contacts.

In electronics the main advantage of the use of polymers is the ease with which they can be processed into required shapes. The resulting circuits are light and flexible. The applications of conductive polymers can be summarized as follows: Fibers, antistatic and other coatings (polyaniline), films, diodes, electroluminescent devices, displays, printed circuit boards, electrochemical windows in houses and cars, conductive fabrics, transistors (for electron circuits of CD players), and light-emitting diodes (laser diodes to read CD's).

Conductive polymers have generated a great interest due to their applications in rechargeable batteries [4], electronic devices [5], gas separation membranes [6], and for enzyme mobilization [7,8]. Their practical use and processibility can be improved. The conductivity can be improved by addition of dopants $[9,10]$. In addition, their practical use and processibility can be improved by strengthening their poor mechanical and physical properties with chemical and electrochemical blending [11-13]. For example, polypyrrole (ppy) has high conductivity and good environmental stability but it has poor physical and mechanical properties, and it is difficult to process. To improve these properties, conducting sequences of polypyrrole were synthesized with poly(methyl methacrylate) [14] (PMMA). The enzyme "urease" is immobilized in conducting thiophene-capped poly(methyl methacrylate) pyrrole matrices [15]. PMMA matrices are used to entrap enzymes. Thiophene-capped PMMA, PPY graft films showed better properties in terms of enzymatic activity, amount of immobilized protein and kinetic properties than PPY films [15]. 
Poly(methyl methacrylate) is currently being used as an implant in many surgical specialties for bone replacement or augmentation, and also as a spacer [16]. PMMA is an acrylic material made of a powdered bone cement copolymer mixed with a monomer liquid MMA [16]. The structural behavior of PMMA bone cement is improved by thermal curing [16]. The purpose of the present study was to prepare ethylene glycol dimethacrylate (EGDMA)-methyl methacrylate (MMA) copolymers to increase the mechanical properties and processibility of EGDMA polymer. The conductivity of EGDMA polymer was increased by using $\mathrm{LiClO}_{4}$ as a dopant. The effect of temperature on conductivity was studied.

In a previous work it was observed that conductivity of EGDMA polymer decreased with increasing temperature. At a certain temperature the conductivity showed a sudden increase [17]. The aim of the present study was to determine if the PMMA homopolymer and its copolymer with EDGMA gave the same characteristic behavior as was obtained for EGDMA homopolymer, in other words, to determine when EGDMA is copolymerized with MMA to increase its mechanical strength, if it will still show the same trend of conductivity change with temperature, and if it is still suitable for use in industry.

\section{Experimental}

\subsection{Materials}

Ethylene glycol dimethacrylate (EDGM) monomer was obtained from Sigma Aldrich Chemical Company (Milwaukee, WI). It was purified of inhibitor by vacuum distillation at $60-80{ }^{\circ} \mathrm{C}$ at 30 torr. 2-2'-Azobisisobutyronitrile (AIBN) initiator was obtained from Polysciences, Inc. (Warrington, PA). It was purified of methanol before use by preparing a solution in methanol. The solution was cooled at 0 to $-5{ }^{\circ} \mathrm{C}$; crystals were collected and dried in a vacuum at room temperature. Methyl methacrylate (MMA) was a product of Aldrich Chemical Company (Milwaukee, WI). It is sold inhibited with 10 ppm 4-methoxyphenol (MEHQ). The inhibitor was removed by washing with $10 \%$ $\mathrm{NaOH}$, deionized water, drying with anhydrous sodium sulfate and distilling at 30 torr and $40-45^{\circ} \mathrm{C}$. Lithium perchlorate $\left(\mathrm{LiClO}_{4}\right)$ was obtained from Mallinckrodt Chemical Works; it was used directly after dissolving in THF. All solvents were reagent grade and were used without purification.

For UV irradiation, a Philips HPR $125 \mathrm{~W}$ mercury vapor UV lamp was used with a maximum wavelength of $254 \mathrm{~nm}$.

IR spectra were taken with deposition from chloroform on $\mathrm{NaCl}$ discs in a Midac M1200 FTIR spectrophotometer.

For conductivity measurements of the polymer solutions, an Omega CDB-420 conductivity meter was used. The conductivities were all measured in solution rather than in the solid state as films because after obtaining polymer, casting them as films is a difficult and time-consuming procedure; also, the casting method is applied for polymers with much higher conductivities. At solid state the conductivity of polymer films are directly measured with van der Pauw (four-probe) method or by coating a fabric surface with polymer, then using the four-probe method.

All samples were degassed and irradiated in quartz tubes of $12 \mathrm{~cm}$ height and $2.8 \mathrm{~cm}$ diameter. A high vacuum system $\left(10^{-4}-10^{-5}\right.$ torr $)$ was used for evacuating monomer solutions. The tubes were irradiated in a horizontal position at a distance of $20 \mathrm{~cm}$ from the UV source. 


\subsection{Preparation of Polymers}

Polyethylene glycol dimethacrylate (PEGDM) was prepared as follows: About $5 \mathrm{~mL}$ distilled EGDMA, $10 \mathrm{~mL}$ THF, and 1\% AIBN initiator were placed in quartz tubes. The tubes were sealed with a septum and connected to the high vacuum system with a syringe needle and degassed to $10^{-4}-10^{-5}$ torr for 5-6 hours. The degassed tubes were then irradiated with the UV source [17]. After 30 minutes of irradiation the obtained polymer was dissolved in THF which is a good solvent for both the monomer and polymer, then precipitated in methanol. The resulting polymer was filtered and dried in a vacuum oven at room temperature to a constant weight. When dopant addition is required, about $0.3-0.4 \mathrm{M}$ dopant was incorporated with the monomer solution system before polymerization or it was added to the polymer solution after polymerization [17].

Poly(methyl methacrylate) (PMMA) was prepared by placing $5 \mathrm{~mL}$ of distilled MMA monomer and $1 \%$ AIBN initiator in a quartz tube. The tube was sealed with a rubber septum and connected to the manifold of the vacuum system with a syringe needle and degassed to $10^{-4}-10^{-5}$ torr for 5-6 hours. The tube was then irradiated by UV radiation at $254 \mathrm{~nm}$ for 30 minutes. After completing the irradiation, the resulting polymer was dissolved in chloroform and precipitated in methanol, filtered and dried at room temperature in a vacuum oven to a constant weight.

\subsection{Preparation of Copolymers}

Monomers were mixed in different volume ratios ( $5 \mathrm{~mL}$ total) in a tube with $1 \%$ AIBN catalyst. To each tube $10 \mathrm{~mL}$ THF was added to complete the volume to $15 \mathrm{~mL}$ (e.g., $1.7 \mathrm{~mL} \mathrm{MMA} \mathrm{+} 3.25 \mathrm{~mL}$ EGDMA $+10 \mathrm{~mL}$ THF $+1 \%$ AIBN). The tube was sealed with a rubber septum and connected to the manifold with a syringe needle and degassed to a high vacuum. The tubes were then irradiated by UV radiation at $254 \mathrm{~nm}$ for 30 minutes. After completing the irradiation, the copolymers were dissolved in chloroform, precipitated in methanol, and filtered and dried at room temperature in a vacuum oven to a constant weight.

For conductivity measurements about $0.125 \mathrm{~g}$ of the PEGDM polymer was dissolved in $12.5 \mathrm{~mL}$ THF solution; the conductivity was measured directly with the conductivity meter using a probe immersed in the polymer solution. The same amount of PMMA polymer $(0.125 \mathrm{~g})$ was dissolved in $37.5 \mathrm{~mL}$ chloroform solution and the conductivity was measured.

The EGDMA-MMA copolymers (about $0.125 \mathrm{~g}$ ) were dissolved in $37.5 \mathrm{~mL}$ chloroform solutions. When dopant addition is required, $0.3-0.4 \mathrm{M}(0.1 \mathrm{~g})$ dopant was incorporated into the polymer or copolymer solution system before polymerization or it was added to the polymer solution after polymerization before the conductivity measurement.

\section{Theory}

\subsection{Mechanisms}

The proper mechanism for the free-radical polymerization of EGDMA and MMA initiated by UV radiation in the presence of initiator is given by the equations in Figures 1-5. These figures show how initiator radical is formed (Figure 1) and how growing EGDMA• (Figure 2) and growing MMA• 
(Figure 3) radicals are obtained, and according to their preference by adding either their own monomer molecules or the monomer molecule of the other constituent, how the copolymerization occurs. The obtained growing EGDMA radical (EGDMA $\bullet$ ) adds its own monomer with a rate constant $k_{11}$ (Figure $4 \mathrm{a}$ ) or it adds MMA monomer with a rate constant $k_{12}$ (Figure $4 \mathrm{~b}$ ).

The obtained MMA radical (MMA•) also adds its own monomer with a rate constant $k_{22}$ (Figure $5 \mathrm{a}$ ) or adds EDGMA monomer with a rate constant $k_{21}$ (Figure $5 \mathrm{~b}$ ).

Figure 1. Formation of initiator radical.

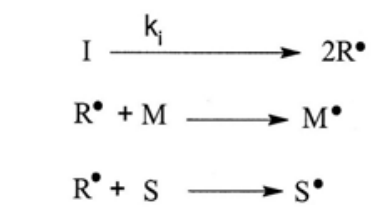<smiles>CC(C)(C)N=NC(C)(C)C#N</smiles>

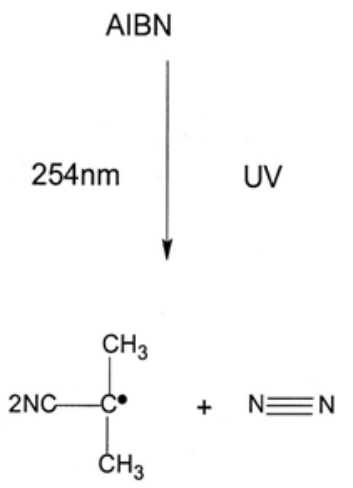

$(\mathrm{R})$

Figure 2. Formation of growing EGDMA radical.<smiles>C=C(C)C(=O)OCCCOC(=O)C(C)=CCCC(C)(C)C#N</smiles>
(Rं) EGDMA<smiles>C=C(C)C(=O)OCCOC(=O)CCC(C)(C)C#N</smiles> 
Figure 3. Growing MMA radical chain.<smiles>COC(=O)C1=CC(C)CCCC1C(C)(C)C#N</smiles>

MMA

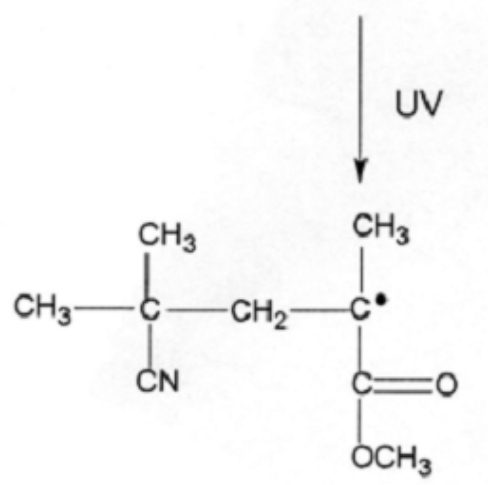

(M9) growing MMA radical chain

Figure 4. a.(left) Growing EGDMA radical adds its own monomer; b.(right) Growing EGDMA radical adds MMA monomer.<smiles>C=C(C)C(=O)OCCOC(=O)CC(C)(C)C#N</smiles><smiles>C=C(C)C(=O)OCCOC(=O)[C](C)C(C)(C)C#N</smiles>

(EGDMA $\left.{ }^{*}\right)$ growing EGDMA radical chain<smiles>C=C(C)C(=O)OCCOC(=O)C(=C)C</smiles>

EGDMA<smiles>CCCCCCC</smiles><smiles>C=C(C)C(=O)OC</smiles>
MMA<smiles>C=C(C)C(=O)OCCOC(=O)C(C)(C)C(C)(C)C#N</smiles><smiles>C=C(C)C(=O)OCCOC(=O)C(C)(C)C</smiles><smiles>C=C(C)C(=O)OCCCOC(=O)C(C)(CC(C)C#N)C(C)(C)C(=O)OC</smiles> 
Figure 5. (a). MMA radical adds its own monomer; (b). MMA radical adds EGDMA monomer.

(a)

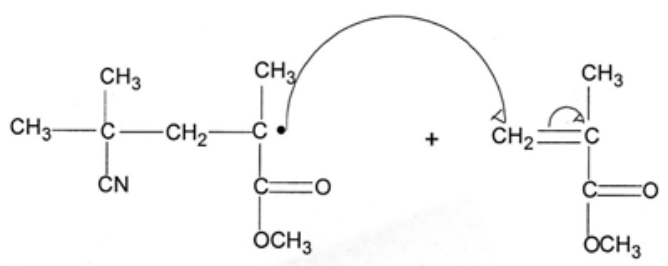

$\mathrm{M}^{\bullet}$
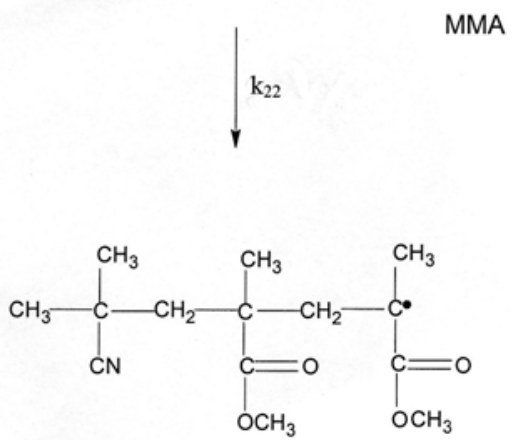

(b)<smiles>COC(=O)C(C)CC(C)(CC(C)(C)C#N)C(=O)OC</smiles>

$\left(M^{*}\right)$ growing MMA radical chain<smiles>C=C(C)C(=O)OCCOC(=O)C(=C)C</smiles>

EGDMA

$\mathrm{k}_{21}$<smiles>C=C(C)C(=O)OCCOC(=O)[C](C)CC(C)(CC(C)(CC(C)(C)C#N)C(=O)OC)C(=O)OC</smiles>

Here $\mathrm{r}_{1}=\mathrm{k}_{11} / \mathrm{k}_{12} \quad \mathrm{r}_{2}=\mathrm{k}_{22} / \mathrm{k}_{21}$ 
All reactions are summarized below:

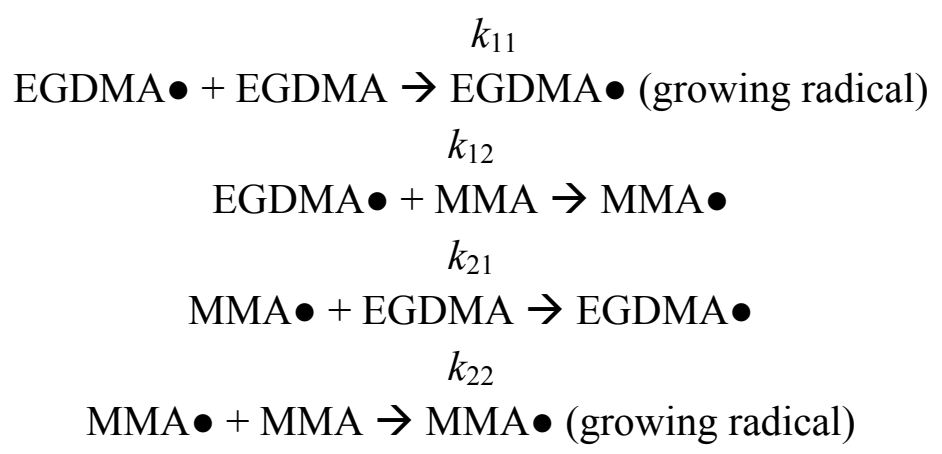

The ratio of $k_{11}$ to $k_{12}$ is considered as the reactivity ratio $r_{1}$, and the ratio of $k_{22}$ to $k_{21}$ is the reactivity ratio $r_{2}$.

For the kinetics the following assumptions were made: Over any short time interval the concentration of free radicals does not change appreciably with time, i.e., $\mathrm{d}$ [radical] $/ \mathrm{dt}=0$. A growing polymer chain's reactivity is determined solely by the last monomer unit added. This reactivity is independent of molecular weight. Propagation is the only reaction of importance since it is repeated many times for each initiation or termination.

\subsection{Rate of Creation of Radicals}

$$
\begin{gathered}
\mathrm{d}[\mathrm{MMA} \bullet] / \mathrm{dt}=k_{12}[\mathrm{EGDMA} \bullet][\mathrm{MMA}]-k_{21}[\mathrm{MMA} \bullet][\mathrm{EGDMA}]=0 \\
\mathrm{~d}[\mathrm{EGDMA} \bullet] / \mathrm{dt}=k_{12}[\mathrm{MMA} \bullet][\mathrm{EGDMA}]-k_{12}[\mathrm{EGDMA} \bullet][\mathrm{MMA}]=0
\end{gathered}
$$

At steady state assumptions these two rates become equal to zero. The expressions

$$
\mathrm{k}_{21}[\mathrm{MMA} \bullet][\mathrm{EGDMA}]=k_{12}[\mathrm{EGDMA} \bullet][\mathrm{MMA}]
$$

and

$$
\mathrm{k}_{12}[\mathrm{EGDMA} \bullet][\mathrm{MMA}]=k_{21}[\mathrm{MMA} \bullet][\mathrm{EGDMA}]
$$

are obtained.

The rates of disappearance of the two monomers may be expressed by the following:

$$
\begin{gathered}
-\mathrm{d}[\mathrm{EGDMA}] / \mathrm{dt}=\mathrm{k}_{11}[\mathrm{EGDMA} \bullet][\mathrm{EGDMA}]+\mathrm{k}_{21}[\mathrm{MMA} \bullet][\mathrm{EGDMA}] \\
-\mathrm{d}[\mathrm{MMA}] / \mathrm{dt}=\mathrm{k}_{22}[\mathrm{MMA} \bullet][\mathrm{MMA}]+k_{12}[\mathrm{EGDMA} \bullet][\mathrm{MMA}]
\end{gathered}
$$

When the first equation is divided by the second equation,

$$
\begin{gathered}
\mathrm{d}[\mathrm{EGDMA}] / \mathrm{d}[\mathrm{MMA}]=\mathrm{k}_{11}[\mathrm{EGDMA} \bullet][\mathrm{EGDMA}]+k_{21}[\mathrm{MMA} \bullet][\mathrm{EGDMA}] / \mathrm{k}_{22}[\mathrm{MMA} \bullet][\mathrm{MMA}]+ \\
k_{12}[\mathrm{EGDMA} \bullet][\mathrm{MMA}]
\end{gathered}
$$

By substitution of Equations 1 and 2 into Equation 3, Equation 4 is obtained.

$$
\begin{gathered}
\mathrm{d}[\mathrm{EGDMA}] / \mathrm{d}[\mathrm{MMA}]=\mathrm{k}_{11}[\mathrm{EGDMA} \bullet][\mathrm{EGDMA}]+k_{12}[\mathrm{EGDMA} \bullet][\mathrm{MMA}] / \mathrm{k}_{22}[\mathrm{MMA} \bullet][\mathrm{MMA}]+ \\
k_{21}[\mathrm{MMA} \bullet][\mathrm{EGDMA}]
\end{gathered}
$$

and by dividing the numerator by $k_{12}$ [EGDMA][MMA] and the denominator by $k_{21}[\mathrm{MMA} \bullet$ [EGDMA], the equation is rearranged as shown in Equation 5.

$$
\mathrm{d}[\mathrm{EGDMA}] / \mathrm{d}[\mathrm{MMA}]=\left(k_{11}[\mathrm{EGDMA}] / k_{12}[\mathrm{MMA}]+1\right) /\left(k_{22}[\mathrm{MMA}] / k_{21}[\mathrm{EGDMA}]+1\right)
$$


If $\mathrm{h}$ is denoted as the mole ratio of monomer 1 to monomer 2 in the copolymer, $\mathrm{h}=\mathrm{d}[\mathrm{EGDMA}] / \mathrm{d}[\mathrm{MMA}]$ and $\mathrm{H}$ is denoted as the same ratio in the monomer feed, $\mathrm{H}=[\mathrm{EGDMA}] /[\mathrm{MMA}]$, and $\mathrm{r}_{1}=k_{11} / \mathrm{k}_{12}$ the ratio of reactivity of monomer 1 toward itself to the reactivity of monomer 1 toward monomer2, and also $r_{2}=k_{22} / \mathrm{k}_{21}$, Equation 5 is reduced to:

$$
\mathrm{h}=\mathrm{r}_{1} \mathrm{H}+1 / \mathrm{r}_{2} \mathrm{H}+1
$$

or by arrangement

$$
\mathrm{H}(1-\mathrm{h}) / \mathrm{h}=\mathrm{r}_{2}-\mathrm{r}_{1}\left(\mathrm{H}^{2} / \mathrm{h}\right)
$$

Equation 6 is obtained. According to this equation, if the left-hand quantity is plotted versus $\mathrm{H}^{2} / \mathrm{h}$, the $y$ intercept will give $r_{2}$ and the slope will be $-r_{1}$ [18]. Here, $r_{1}$ indicates the reactivity ratio of EGDMA monomer and $r_{2}$ indicates the reactivty ratio of MMA monomer.

In this study reactivity ratios were determined by using Equation 6. For this purpose UV light was used as a photochemical initiator and IR spectroscopy was used for the determination of the instantanous composition of copolymers.

\section{Results and Discussion}

\subsection{IR Analysis of EGDMA/MMA Copolymers}

For IR analysis $4-10 \times 10^{-3}$ gram copolymer samples were dissolved in $1.0 \mathrm{~mL}$ chloroform solutions. About 3 drops of each solution were placed uniformly between two solid $\mathrm{NaCl}$ discs and IR spectra were taken.

A wavelength was sought at which one of the homopolymers and its copolymer showed a characteristic peak where the homopolymer of the other constituent did not absorb. By preparing solutions of various concentrations, spectra were taken for each copolymer as well as its corresponding homopolymer. A calibration curve was obtained by plotting the absorbance of one of the homopolymers at a specific wavelength against known concentrations. The absorbance of copolymer samples at this particular wavelength was measured and the corresponding percentages of the monomer in the copolymers were calculated. The IR spectra of PMMA and PEGDM homopolymers are shown in Figures 6 and 7, respectively.

Figure 6. IR spectrum of poly(methyl methylacrylate) (PMMA).

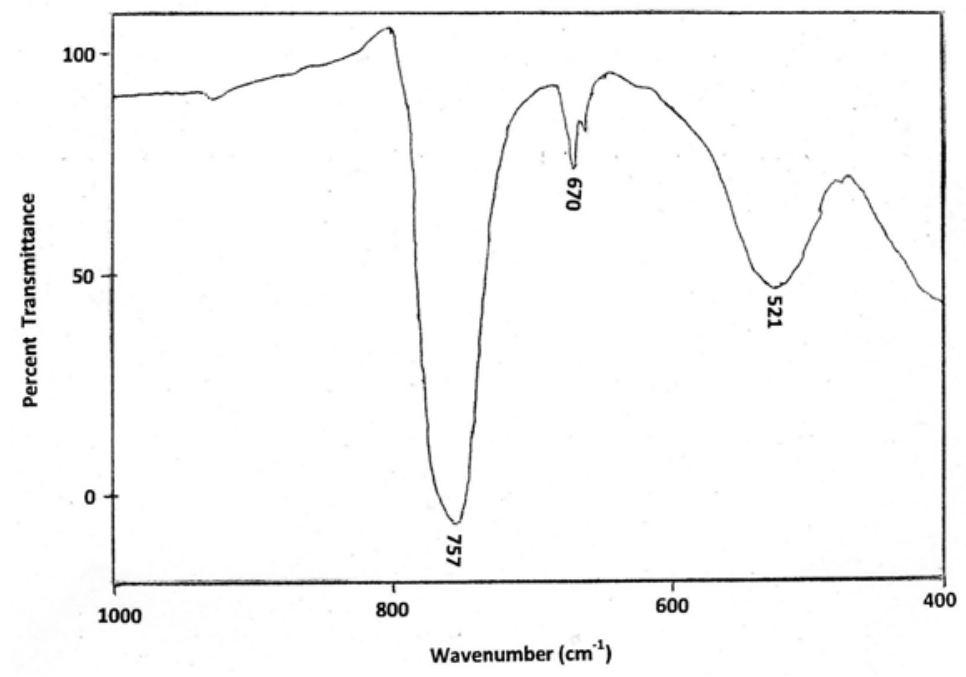


Figure 7. IR spectrum of poly(ethylene glycol dimethacrylate) (PEGDMA).

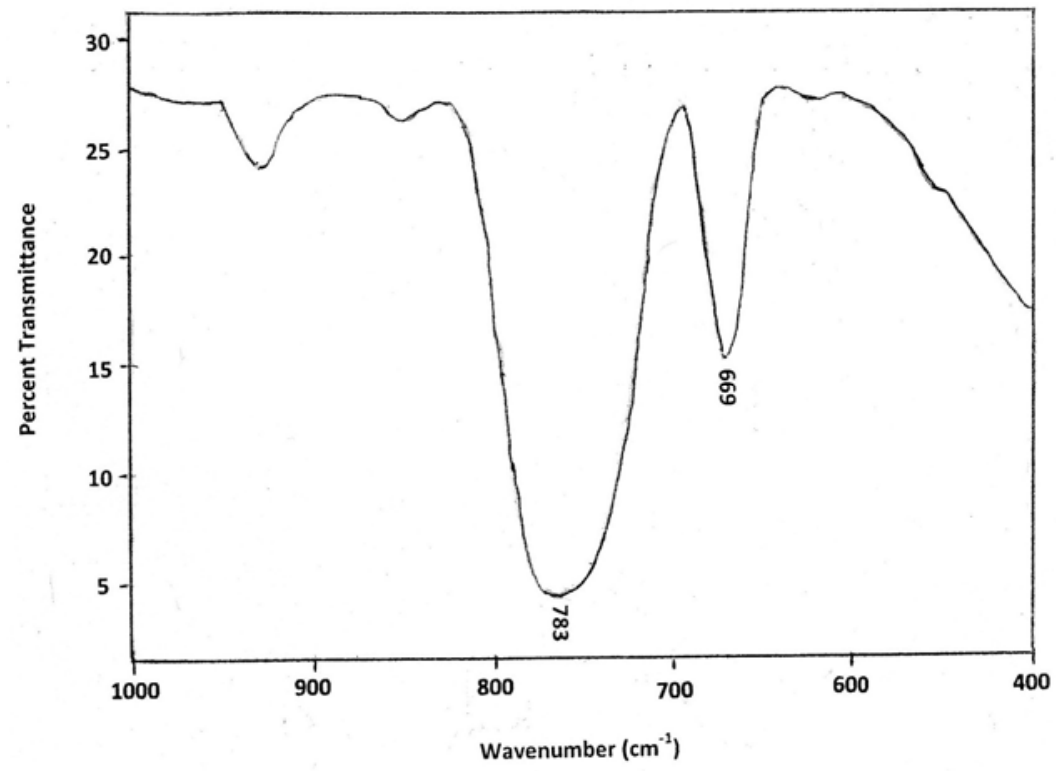

For copolymers, the absorption at $520 \mathrm{~cm}^{-1}$ was chosen as a reference which was a characteristic peak for PMMA (Figure 6). The absorbance of each peak at $520 \mathrm{~cm}^{-1}$ in IR spectra was calculated as shown in Figure 8. An absorption peak at $520-540 \mathrm{~cm}^{-1}$ was chosen for analysis where only MMA homopolymer and all copolymer samples showed absorption (Figure 6) but EGDMA homopolymer did not (Figure 7).

Figure 8. Baseline method for determining absorbance from infrared spectrum.

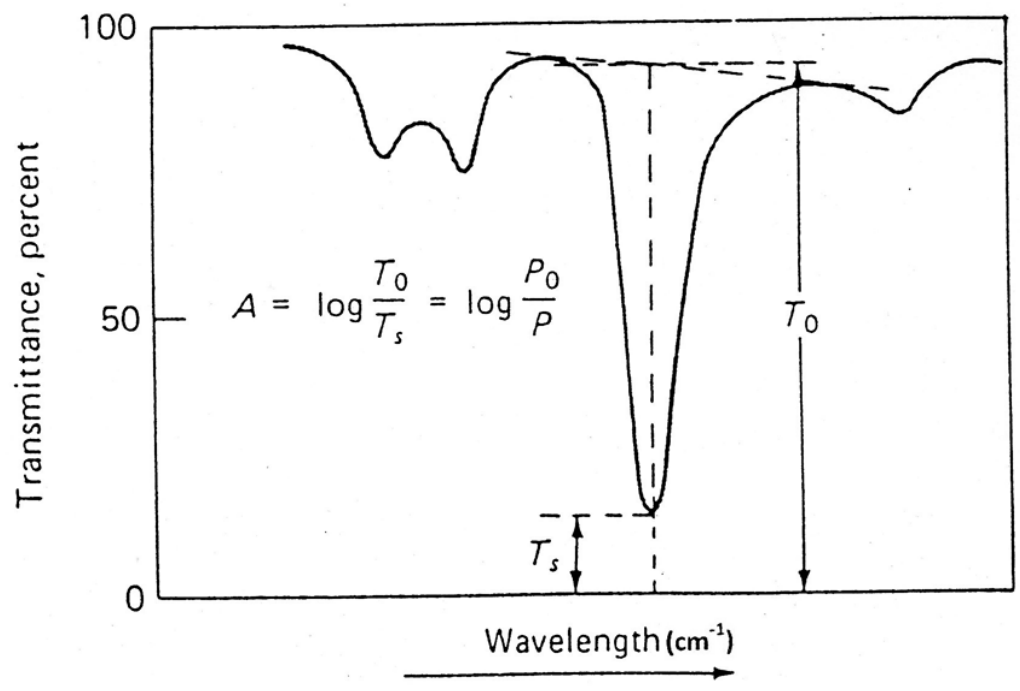

Different concentrations of MMA homopolymer $\left(4.0-8.0 \times 10^{-3} \mathrm{~g} / \mathrm{mL}\right)$ were prepared in chloroform solutions and absorbance values were calculated at $520-540 \mathrm{~cm}^{-1}$. Figure 9 shows the calibration curve. Different compositions of MMA/EGDMA monomer mixtures were prepared in varying feed ratios, as indicated in Table 1 . The copolymers were analyzed in chloroform solution by their absorbance at $520-540 \mathrm{~cm}^{-1}$, as indicated in Table 2 . 
Figure 9. MMA calibration curve for copolymer analysis.

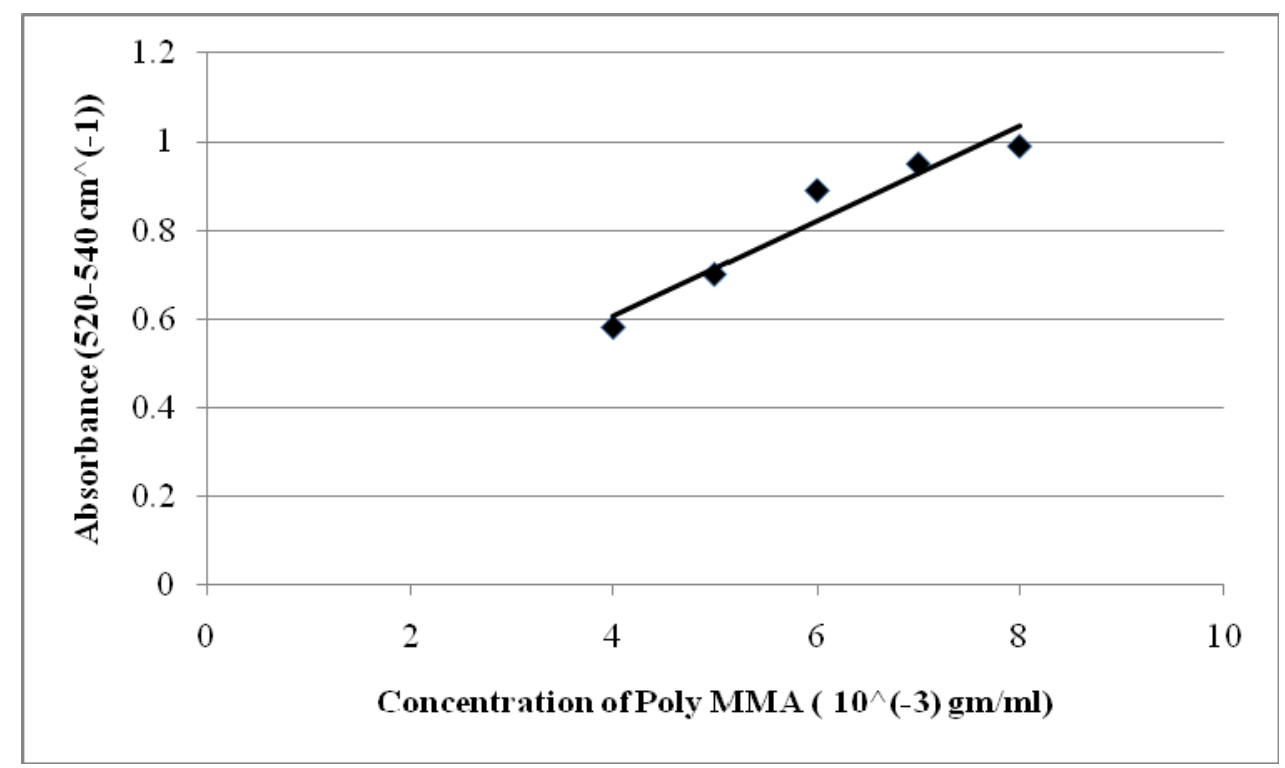

Table 1. Monomer Feed Preparations.

\begin{tabular}{ccccc}
\hline Copolymer & MMA $(\mathrm{mL})$ & EGDMA $(\mathrm{mL})$ & THF $(\mathrm{mL})$ & $\begin{array}{c}\text { Volume ratio of EGDMA to } \\
\text { MMA in feed }\end{array}$ \\
\hline 1 & 0.75 & 4.25 & 10 & 5.66 \\
2 & 1.00 & 4.00 & 10 & 4.00 \\
3 & 1.25 & 3.75 & 10 & 3.00 \\
4 & 1.50 & 3.50 & 10 & 2.33 \\
5 & 1.75 & 3.25 & 10 & 1.86 \\
\hline
\end{tabular}

Table 2. EGDMA/MMA Copolymer Analysis (I) by IR Spectroscopy.

\begin{tabular}{|c|c|c|c|c|c|c|c|}
\hline Copolymer & $\begin{array}{l}\text { (A)Copolymer } \\
\text { Taken } \mathrm{g} / \mathrm{mL} \text { in } \\
\text { chl } * 10^{3}\end{array}$ & $\begin{array}{c}\text { Absorbance } \\
\text { at } 520-540 \\
\mathrm{~cm}^{-1} \\
\end{array}$ & $\begin{array}{c}(\mathrm{B})(\mathrm{MMA})_{\mathrm{B}}{ }^{1} \\
* 10^{3} \text { in chl. }\end{array}$ & $\begin{array}{c}(\mathrm{A}-\mathrm{B}) \\
(\mathrm{EGDMA})_{\mathrm{A}-\mathrm{B}}{ }^{2} \\
* 10^{3} \text { in chl. }\end{array}$ & $\begin{array}{c}\text { [MMA }] \\
\mathrm{mol} / \mathrm{L} \text { in co- } \\
\text { polymer }\end{array}$ & $\begin{array}{l}\text { [EDGMA] } \\
\text { mol/L in } \\
\text { copolymer }\end{array}$ & $\begin{array}{l}\left(\mathrm{F}_{2}\right) \mathrm{mol} \% \\
\text { of MMA in } \\
\text { copolymer }\end{array}$ \\
\hline 1 & 7.0 & 0.27 & 1.35 & 5.66 & 0.01348 & 0.02855 & 32.09 \\
\hline 2 & 4.2 & 0.32 & 1.80 & 2.40 & 0.01797 & 0.01210 & 59.76 \\
\hline 3 & 5.4 & 0.37 & 2.20 & 5.03 & 0.02190 & 0.02537 & 46.41 \\
\hline 4 & 7.7 & 0.48 & 3.10 & 4.61 & 0.03096 & 0.02325 & 57.12 \\
\hline 5 & 9.9/ & 0.85 & 6.30 & 3.60 & 0.06292 & 0.01816 & 77.60 \\
\hline
\end{tabular}

The concentration of MMA was calclulated in copolymer sample (B) by using the calibration curve. By taking the difference between the amount of copolymer taken (A) and the amount of MMA found (B), the amount of EGDMA in copolymer was calculated. From the results shown in Table 2, the mole ratios of EGDMA to MMA in copolymer (h) were calculated. Table 3 shows the conversion of these concentrations in mol/L. Table 4 shows the mole ratios of EGDMA/MMA in copolymer $(\mathrm{h})$ and in the monomer feed $(\mathrm{H})$; both are calculated in $\mathrm{mol} / \mathrm{L}$. 
Table 3. EGDMA/MMACopolymer Analysis (II) by IR Spectroscopy.

\begin{tabular}{ccccc}
\hline Copolymer & $\begin{array}{c}\text { [EGDMA]/[MMA] } \\
\text { volume ratio in feed } \\
\text { from Table 1 }\end{array}$ & $\begin{array}{c}\text { [MMA] in feed, } \\
\text { mol/L, in } \\
\text { chloroform }\end{array}$ & $\begin{array}{c}\text { [EGDMA in feed, } \\
\text { mol/L, in } \\
\text { chloroform }\end{array}$ & $\begin{array}{c}\left(\mathrm{f}_{2}\right) \text { mol \% } \\
\text { MMA in feed }\end{array}$ \\
\hline 1 & 5.66 & 0.467 & 1.502 & 23.72 \\
2 & 4.00 & 0.623 & 1.414 & 30.20 \\
3 & 3.00 & 0.779 & 1.325 & 37.02 \\
4 & 2.33 & 0.935 & 1.237 & 43.05 \\
5 & 1.86 & 1.091 & 1.149 & 48.71 \\
\hline
\end{tabular}

Table 4. EGDMA/MMA Copolymer Analysis by IR Spectroscopy (III).

\begin{tabular}{ccccc}
\hline Copolymer No. $\begin{array}{c}\text { Mole ratio in feed } \\
\text { [EGDMA][MMA] } \\
\text { from Table 3 }\end{array}$ & $\begin{array}{c}\text { Mole ratio in copolymer } \\
\mathrm{H}=[\text { EGDMA]/[MMA] }\end{array}$ & $\mathrm{H}(1-\mathrm{h}) / \mathrm{h}$ & $\mathrm{H}^{2} / \mathrm{h}$ \\
\hline 1 & 3.216 & 2.118 & -1.697 & 4.883 \\
2 & 2.269 & 1.330 & -0.563 & 3.870 \\
3 & 1.701 & 1.155 & -0.228 & 2.505 \\
4 & 1.323 & 0.751 & 0.439 & 2.331 \\
\hline \multicolumn{4}{l}{$\mathrm{H}=$ Mole ratio in feed; $\mathrm{h}=$ Mole ratio in copolymer }
\end{tabular}

According to Equation 6, when $\mathrm{H}(1-\mathrm{h}) / \mathrm{h}$ is plotted versus $\mathrm{H}^{2} / \mathrm{h}$, the y intercept should give $\mathrm{r}_{2}$ and the slope gives $-r_{1}$ values. Figure 10 shows such a plot where $r_{1}$ was calculated as 0.6993 and $r_{2}$ as 1.8635 .

Figure 10. $\mathrm{H}(1-\mathrm{h}) / \mathrm{h} v s . H^{2} / \mathrm{h}$ plot for reactivity ratio determination of monomers.

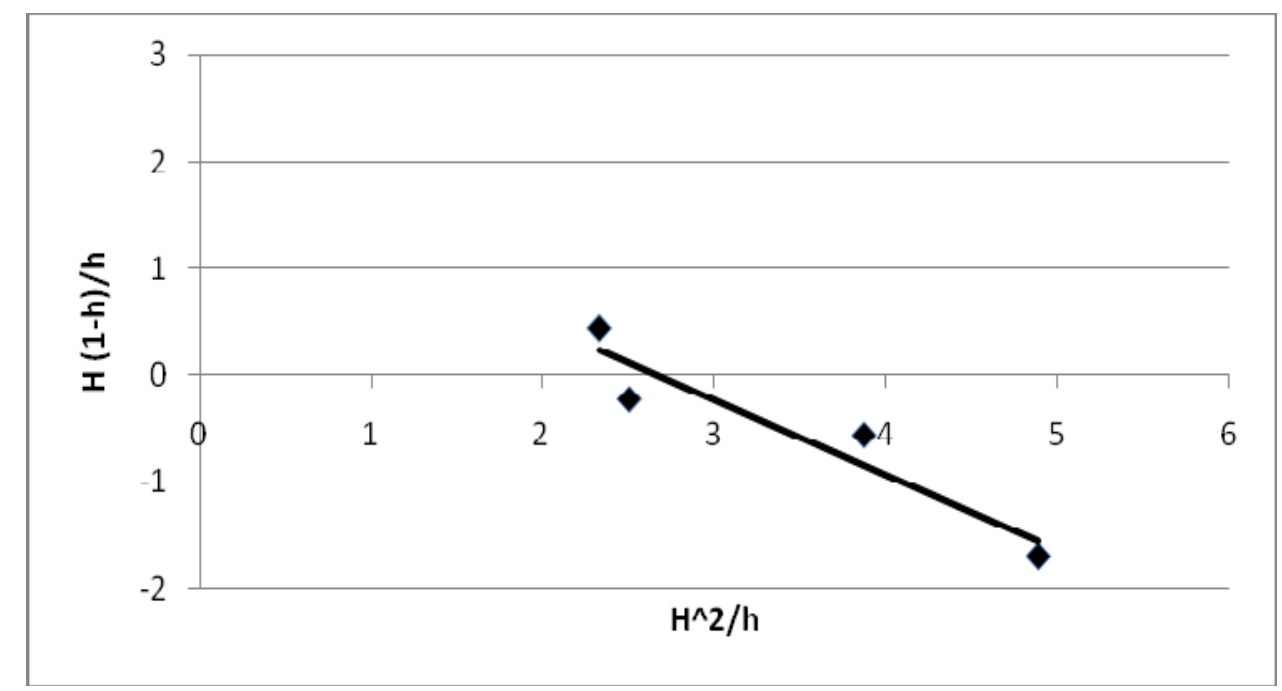

The mole percentages of MMA in copolymer F2 and in monomer feed (f2) are calculated as shown in Tables 2 and 3, respectively. Table 5 summarizes the results. Figure 11 shows a plot of instantanous composition of copolymer F2 (mole percent of MMA in copolymer) as a function of monomer composition $\mathrm{f} 2$ (mole percent of MMA in the feed). The shape of the curve suggests the type of copolymer obtained (alternating, block, random, etc.) [19]. 
Table 5. EGDMA/MMA copolymer analysis by IR Spectroscopy (IV).

\begin{tabular}{cc}
\hline$f_{2}(\mathrm{~mol} \% \mathrm{MMA}$ in feed $)$ & $F_{2}(\mathrm{~mol} \%$ MMA in Copolymer $)$ \\
\hline 23.72 & 32.09 \\
37.02 & 46.41 \\
43.05 & 57.12 \\
48.71 & 77.60 \\
\hline
\end{tabular}

Figure 11. Mol percents of MMA in copolymer $v s$. in monomer feed.

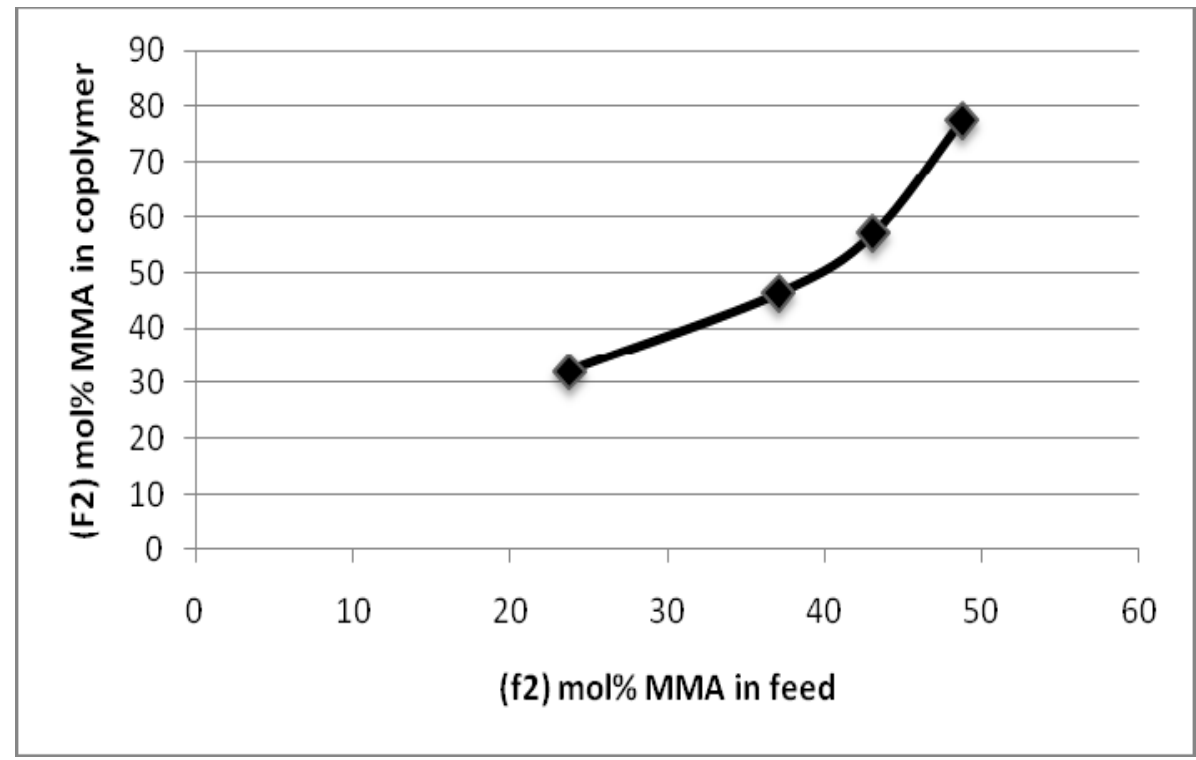

This copolymer shows reactivity ratios as $\mathrm{r} 1<1$ and other $\mathrm{r} 2>1$. Thus, $\mathrm{r} 1>1$ means that the radical $\mathrm{M} 1$ prefers to add $\mathrm{M} 1$ and $\mathrm{r}_{1}<1$ means that it prefers to add M2. A copolymer system is said to be ideal when the two radicals show the same preference for adding one monomer over the other [20]. Therefore, $k 11 / k 12=k 21 / k 22$, or $\mathrm{r} 1=1 / \mathrm{r} 2$, or $\mathrm{r} 1 \mathrm{r} 2=1$. If $\mathrm{r} 1>1$ and $\mathrm{r} 2<1$ or vice versa, there will be no critical composition. In this case, the end group of the growing chain has no influence on the rate of addition, and the two types of units are arranged at random along the chain [21]. The copolymer equation then reduces to $\mathrm{d}(\mathrm{M} 1) / \mathrm{d}(\mathrm{M} 2)=\mathrm{r} 1(\mathrm{M} 1 / \mathrm{M} 2)$.

\subsection{Conductivity Change of Monomers and Copolymers with Temperature and Dopant}

The conductivity of PEGDMA (when dopant was added after polymerization) showed a minimum in conductivity vs. temperature plot, as shown in Figure 12. The results are presented in Table 6. At first a decrease in conductivity with increasing temperature (up to $18.2{ }^{\circ} \mathrm{C}$ ) is seen; then it shows a sudden increase [17].

Figures 13 and 14 show the conductivity values of PMMA without and with dopant $\left(\mathrm{LiClO}_{4}\right)$ at different temperatures. They indicate the same kind of behavior seen with PEGDMA; minimum values were observed at 20 and $22{ }^{\circ} \mathrm{C}$, respectively.

Figures 15 and 16 show the plots of one of the copolymers (i.e., 5\% MMA and 95\% EGDMA) prepared without and with dopant, respectively. They both showed a minimum value at around $24{ }^{\circ} \mathrm{C}$. These plots show that addition of dopant increased the conductivity about 775 times. Another 
copolymer (20\% MMA and 80\% EGDMA) (copolymer II) prepared without and with dopant, and the change of the conductivity values with temperature, as seen in Figures 17 and 18, respectively. They both show a minimum value at around $22{ }^{\circ} \mathrm{C}$. The plots show that addition of dopant increased the conductivity about 100 times.

It is observed that as the MMA percentage increases in the copolymer, conductivity values reduce from millisiemens to microsiemens. Also, as MMA percentages in the copolymer increases in the feed, the jump in temperature values gets smaller.

The conductivity of PEGDMA with dopant $\left(\mathrm{LiClO}_{4}\right)$ shows values in

the millisiemens range (Table 6, Figure 12) (e.g., $9.0 \mathrm{mS}$ at $26^{\circ} \mathrm{C}$ ) [17]. The conductivity of PMMA with the same dopant shows much smaller values than PEGDMA, in microsiemens range (Figure 14) (e.g., $24 \mu \mathrm{S}$ at $25^{\circ} \mathrm{C}$ ).

Figure 12. Conductivity vs. temperature change of PEGDMA with dopant $\mathrm{LiClO}_{4}$ (1 hr irradiation).

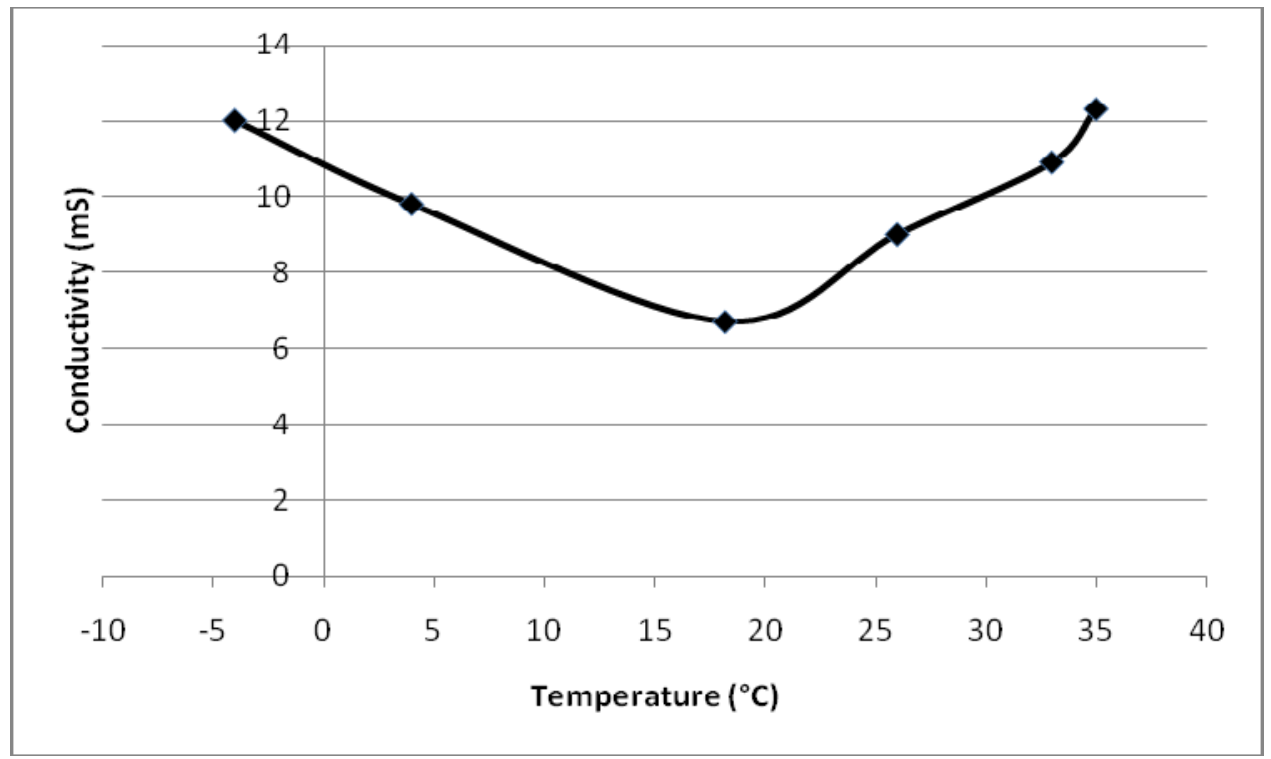

Table 6. Conductivity change of PEGDMA with $\mathrm{LiClO}_{4}$ dopant at different temperatures.

\begin{tabular}{cc}
\hline Temperature $\left({ }^{\circ} \mathrm{C}\right)$ & Conductivity $(\mu \mathrm{S})$ \\
\hline 35.0 & 12.3 \\
33.0 & 10.9 \\
26.0 & 9.0 \\
18.2 & 6.7 \\
4.0 & 9.8 \\
-4.0 & 12.0 \\
\hline$\left(0.125 \mathrm{~g}\right.$ PEGDMA $\left.+12.5 \mathrm{~mL} \mathrm{THF}+0.347 \mathrm{M} \mathrm{LiClO}_{4}[17]\right)$
\end{tabular}


Figure 13. Conductivity $v s$. temperature change of PMMA without dopant.

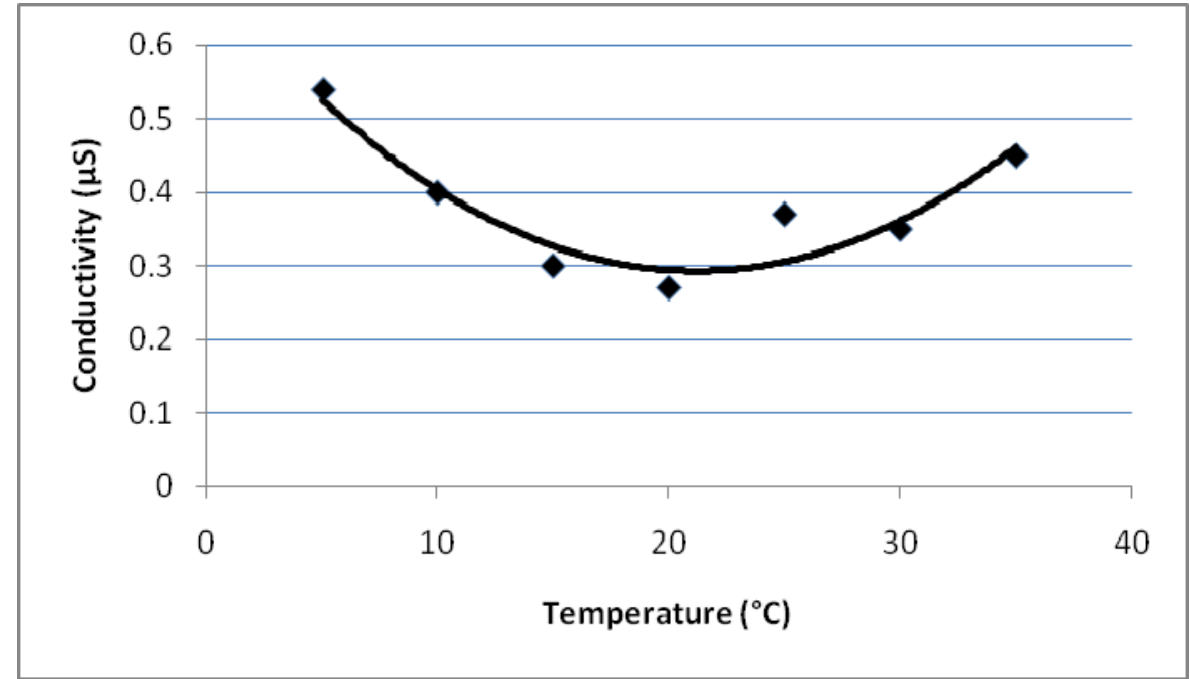

Figure 14. Conductivity $v s$. temperature change of PMMA with dopant $\left(\mathrm{LiClO}_{4}\right)$.

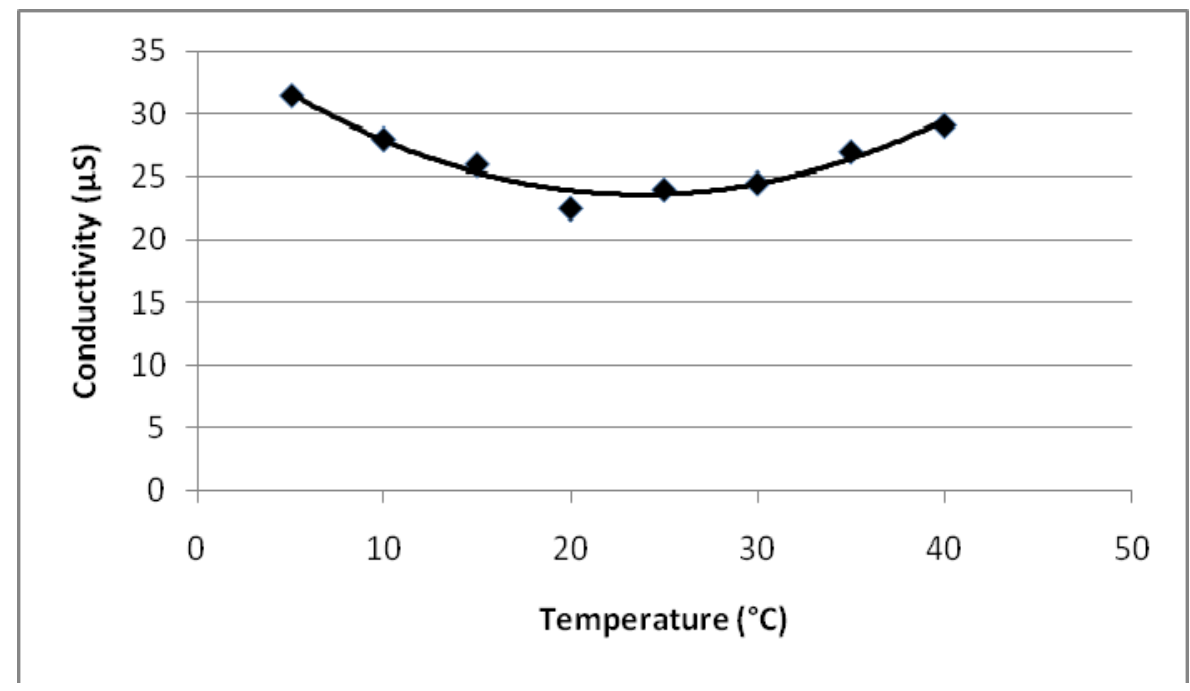

Figure 15. Conductivity vs. temperature change of copolymer (I) without dopant. Copolymer (I): (5\% MMA, 95\% EGDMA in monomer feed).

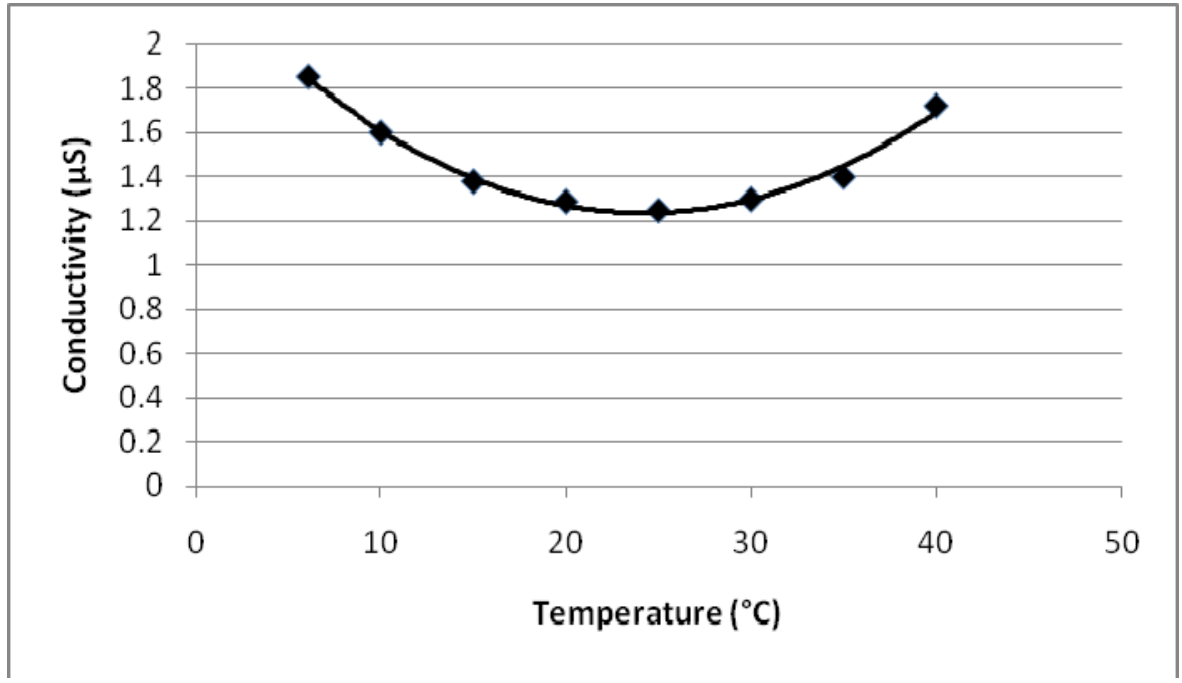


Figure 16. Conductivity $v$ s. temperature change of copolymer (I) with dopant $\left(\mathrm{LiClO}_{4}\right)$. Copolymer (I): (5\% MMA, 95\% EGDMA in monomer feed).

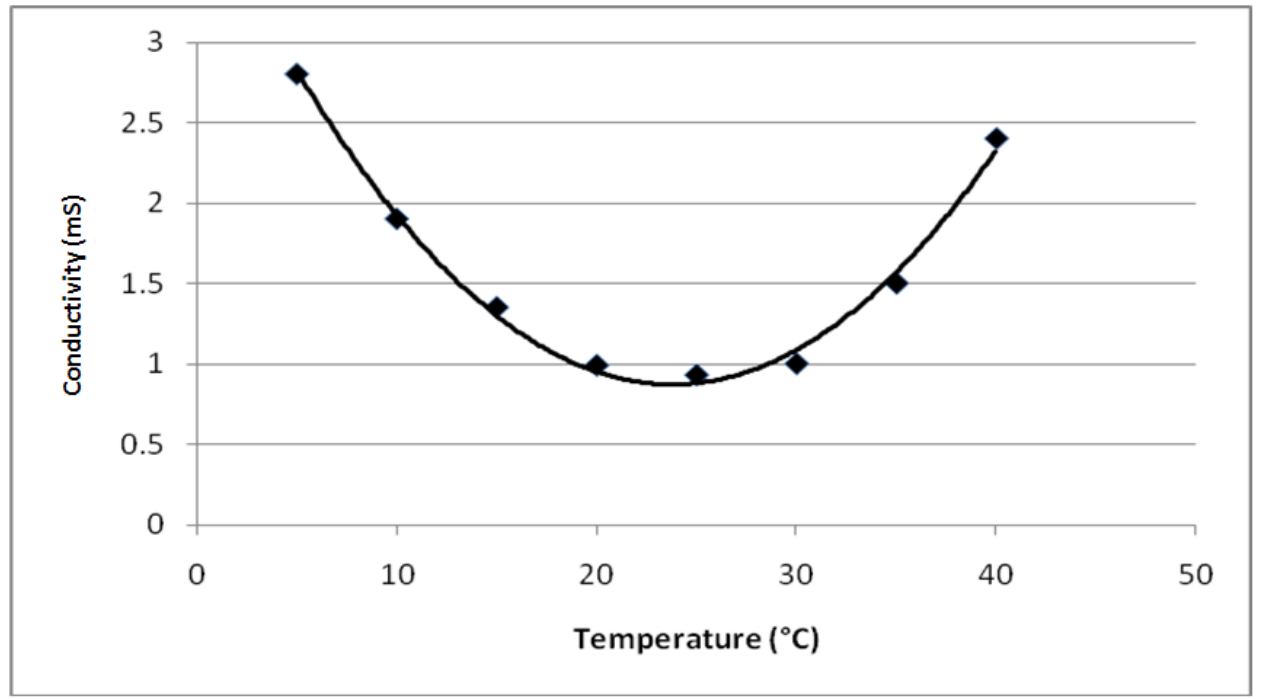

Figure 17. Conductivity $v s$. temperature change of copolymer (II) without dopant. Copolymer (II): (20\% MMA, 80\% EGDMA in monomer feed).

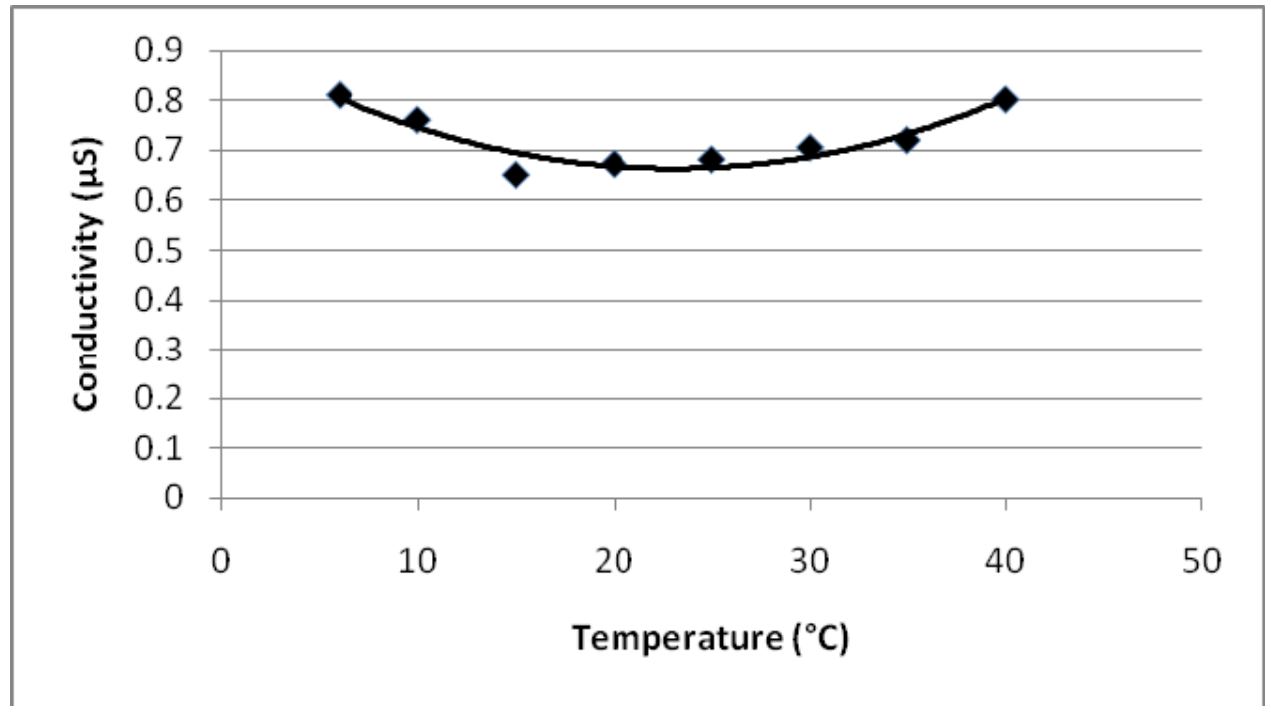

The MMA/EGDMA copolymer containing 5\% MMA in the feed with dopant shows conductivity values in the millisiemens range with a value of $0.93 \mathrm{mS}$ at $25^{\circ} \mathrm{C}$ (Figure 16). The same copolymer without dopant shows conductivity in the $\mu \mathrm{S}$ region (Figure 15); at $25^{\circ} \mathrm{C}$ this value is $1.2 \mu \mathrm{S}$. Dopant increases the conductivity about 775 times. When the MMA percentage increases in the copolymer, such as 20\% MMA in the feed, without dopant these values fall into the microsiemens range with a value of $69 \mu \mathrm{S}(0.069 \mathrm{mS})$ at $25{ }^{\circ} \mathrm{C}$ (Figure 17). With dopant at $25^{\circ} \mathrm{C}$, the conductivity is $69 \mu \mathrm{S}$ (Figure 18). Dopant increased the conducitvity about 100 times. As the MMA percentage increases in the copolymer, the conductivity values decrease from the $\mathrm{mS}$ to the $\mu \mathrm{S}$ region. This is consistent with the fact that PMMA has a lower conductivity than PEGDMA. 
Figure 18. Conductivity vs. temperature change of copolymer (II) with dopant $\left(\mathrm{LiClO}_{4}\right)$. Copolymer (II): (20\% MMA, 80\% EGDMA in monomer feed).

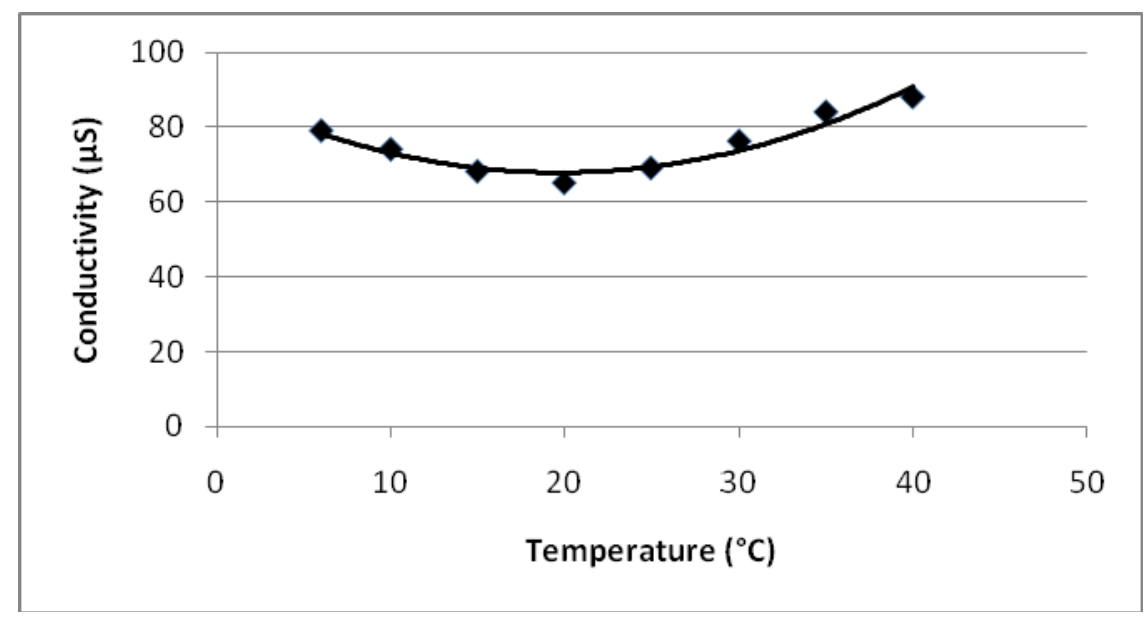

The results show that the conductivity of both PEGDMA and PMMA increases with dopant; however, conductivity values of PEGDMA are in the $\mathrm{mS}$ region, and PMMA is in the $\mu \mathrm{S}$ region. As the MMA percentage increases in the copolymer the conductivity decreases from the $\mathrm{mS}$ to the $\mu \mathrm{S}$ region.

\subsection{Copolymer Conversion}

Copolymerization was performed by UV irradiation and high percentages of copolymer were obtained. The effect of each monomer on copolymer conversion was studied. Conversions were calculated by the ratio of initial mass of feed to the final mass of copolymer. Initial masses of the monomers were determined by using volumes and densities. (For example, the copolymer I for this study was prepared as $4.0 \mathrm{~mL}$ MMA, $1.0 \mathrm{~mL}$ EGDMA and 10mL THF with $1 \%$ catalyst in the feed). Figures 19 and 20 are the plots of weight percent copolymer conversion versus weight percent of MMA in the feed and weight percent of EGDMA in the feed, respectively. As the MMA percentage in the monomer feed increases, the percent conversion decreases (Figure 19); and as the EGDMA percentage increases in the feed, the percent conversion increases (Figure 20).

Figure 19. Copolymer conversion (wt \%) vs. wt \% of MMA in feed.

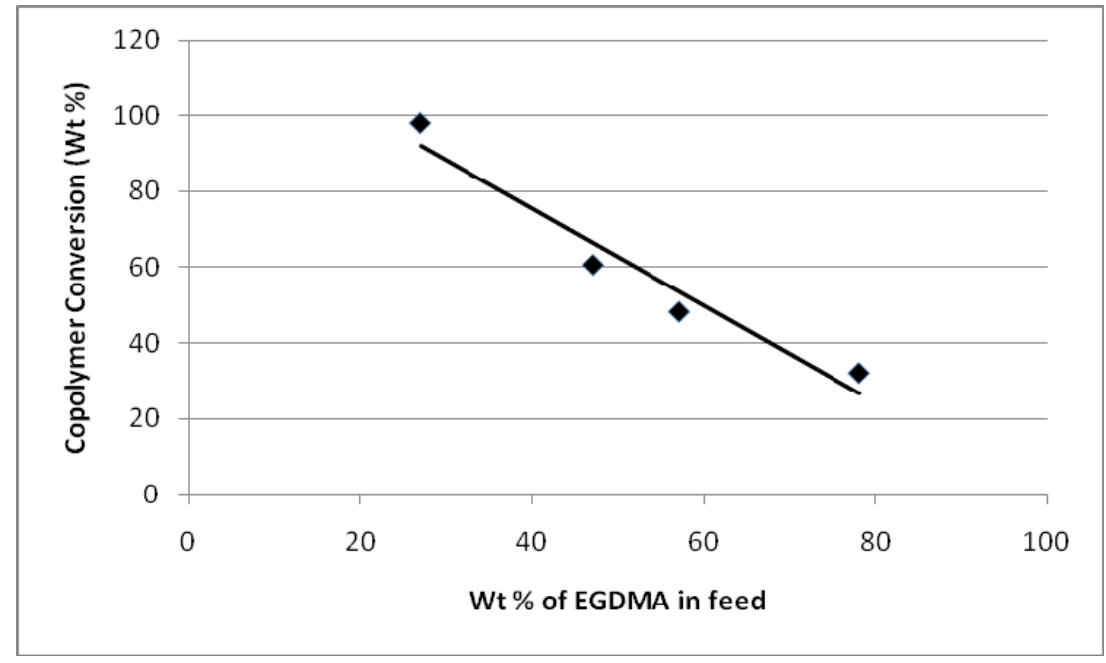


Figure 20. Copolymer conversion (wt \%) vs. wt \% of EGDMA in feed.

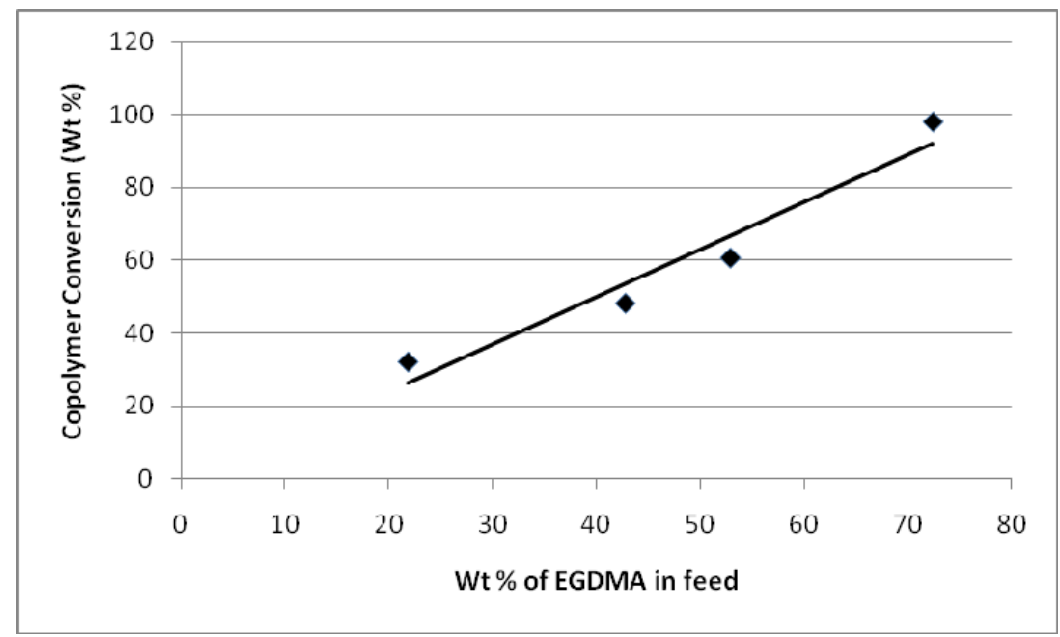

\subsection{Activation Energy Determination for the Reaction of EGDMA/MMA Copolymer with Lithium}

\section{Perchlorate}

The measurement of conductivity change with time provides an excellent way to follow the kinetics of the reaction. Even though one does not know the rate law for a chemical reaction, it is possible to use the Arrhenius expression to calculate the effect of temperature on reaction rate. When conductivity changes were measured as a function of time, immediately after addition of dopant, a sudden increase in conductivity was observed as the reaction proceeds; the increasing rate slows down and reaches a constant value at the completion of the reaction.

Supposing the times required to reach a certain extent of the reaction at two different temperatures, $\mathrm{T}_{1}$ and $\mathrm{T}_{2}$ are $\zeta_{1}$ and $\zeta_{2}$, respectively, since:

$$
\zeta_{1}=\mathrm{e}^{-\mathrm{Ea} / \mathrm{RT}}
$$

therefore,

$$
\ln \left(\zeta_{1} / \zeta_{2}\right)=\mathrm{E}_{\mathrm{a}} / \mathrm{R}\left(1 / \mathrm{T}_{1}-1 / \mathrm{T}_{2}\right)
$$

is obtained. From Equation 8, the activation energy, $\mathrm{E}_{\mathrm{a}}$, for the interaction of copolymer I (5\% MMA and 95\% EGDMA) with perchlorate ion is determined as $31.5 \mathrm{KJ} / \mathrm{mol}$. The activation energy of EGDMA homopolymer with lithium perchlorate was calculated to be $54.7 \mathrm{KJ} / \mathrm{mol}$ in a previous study [17]. For this system at $25{ }^{\circ} \mathrm{C}$ reaction completion takes 141 minutes; at $43{ }^{\circ} \mathrm{C}$ the reaction was completed in 291 minutes. The reaction completion times at different temperatures were determined for the same system and are tabulated in Table 7. A graph of reaction completion time versus temperature (Figure 21) shows that as the temperature increases, reaction completion time increases as well.

When conductivities were plotted versus temperature, Figures 12-18 were obtained. These figures have potential interest for industrial applications of these polymers and copolymers. First, each shows an initial decrease in conductivity with increasing temperature; then, after reaching a minimum value, both copolymers showed the same trend of increasing conductivity with temperature. This indicates the conformational changes of the polymer molecules owing to either crankshaft-type motion about the 
chains or to rotation of methyl groups. Thermal energy is converted into electronic excitation after reaching a minimum value with increasing temperature.

When EGDMA is copolymerized with MMA to increase its mechanical properties, these copolymers still show the same trend of conductivity change with temperature, as was observed for PEGMA [22], even though conductivity of the copolymers decreases slightly with increasing percentage of MMA, compared to PEGMA homopolymer itself. Therefore, potential interest in using these copolymers in industry as a thermal switch still exists, in addition to enhance mechanical strength in the presence of MMA.

Figure 21. Temperature vs. Reaction Completion Time of Copolymer with dopant.

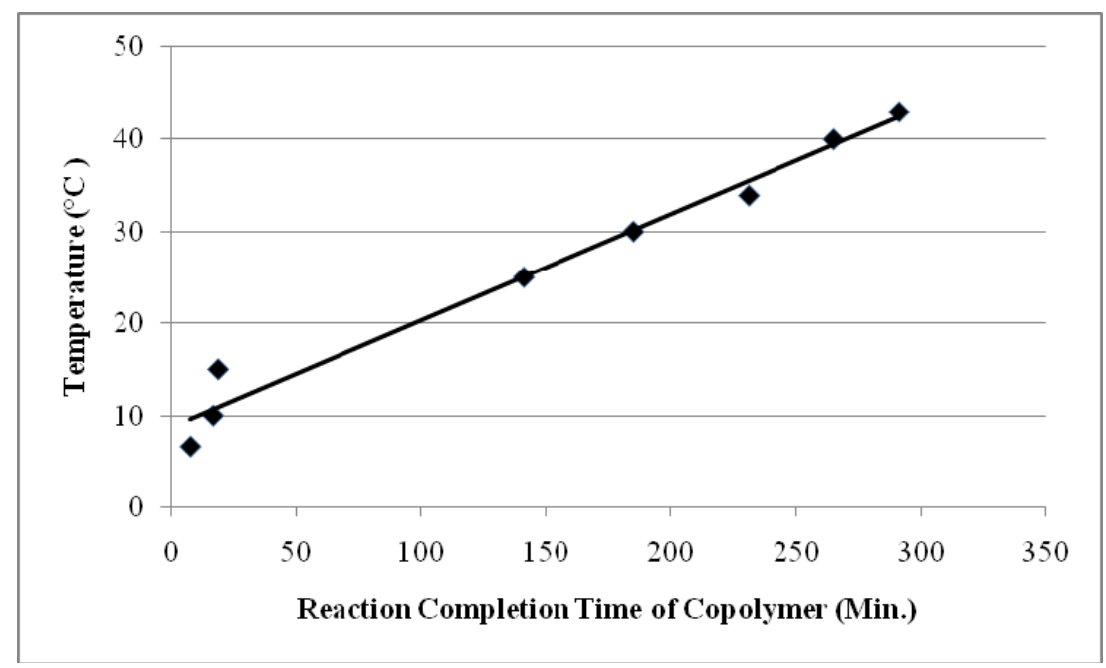

Table 7. Temperature vs. Reaction Completion Time of Copolymer with Dopant.

\begin{tabular}{cc} 
Temperature $\left({ }^{\circ} \mathrm{C}\right)$ & Reaction completion time of copolymer with dopant $\mathrm{LiClO}_{4}(\mathrm{Min})$. \\
\hline 6.5 & 8 \\
10.0 & 17 \\
15.0 & 19 \\
25.0 & 141 \\
30.0 & 185 \\
33.9 & 231 \\
40.0 & 265 \\
43.0 & 291 \\
\hline$(4.75 \mathrm{~mL}$ EGDMA $+0.25 \mathrm{~mL}$ MMA $+10 \mathrm{~mL}$ THF $+10 \%$ AIBN in monomer feed $)$.
\end{tabular}

\section{Conclusions}

1. Using IR spectroscopy of PEGDMA and PMMA homopolymers and their copolymers, the reactivity ratio of EGDMA $\left(\mathrm{r}_{2}\right)$ and MMA $\left(\mathrm{r}_{1}\right)$ were calculated as 0.6993 and 1.8635 , respectively.

2. The conductivities of PEGDMA ( $\mathrm{mS}$ region) is much greater than the conductivities of PMMA $(\mu \mathrm{S}$ region).

3. The conductivities of PEGDMA and PMMA both increase with added dopant, $\mathrm{LiClO}_{4}$. 
4. As the MMA concentration in the polymer increases, the conductivity value decreases $(\mathrm{mS}$ to $\mu \mathrm{S})$.

5. As the MMA percentage in the monomer feed increases, the percent conversion (polymerization) decreases.

6. Conductivity vs. temperature graph for PEGDMA shows a minimum at $18{ }^{\circ} \mathrm{C}$. PMMA and PEGDMA/PMMA copolymers also show the same kind of behavior, with minimum values observed at $22-24{ }^{\circ} \mathrm{C}$. This indicates that these polymers first act as a conductor, then after a minimum temperature become semiconductors and can be potentially used to control the current in electrical devices via temperature change (thermal switch).

7. The measurement of conductivity change with time provides an excellent and new way to follow the kinetics of the copolymer-dopant reactions. By measuring the reaction completion times at different temperatures of the PEGDMA/MMA copolymer, activation energy of interaction with perchlorate ion was determined to be $31.52 \mathrm{~kJ} / \mathrm{mol}$. For PEGDMA alone this value was found to be $54.7 \mathrm{~kJ} / \mathrm{mol}$. As the temperature increases, the reaction completion time also increases.

8. When EGDMA is copolymerized with MMA to increase its mechanical properties, copolymers still show the same trend of conductivity change with temperature even though the conductivity of the copolymer decreases slightly with increasing percentage of MMA. Therefore, interest in using these copolymers in industry as thermal switches still exists.

\section{References}

1. Hush, N.S. An Overview of the First Half-Centruy of Molecular Electronics. Ann. N.Y. Acad. Sci. 2003, 1006, 1-20.

2. McGiness, J.; Corry, P.; Proctor, P. Amorphous semiconductor switching in melanins. Science 1974, 183, 853-855.

3. Bhadra, S.D.; Nikhil, K.S.; Lee, J.H. Progress in preparation, processing and applications of polyaniline. Prog. Polym. Sci. 2009, 34, 783-810.

4. Peres, R.C.D.; DePaoli, M.A.; Panero, S.; Scrosati, B. A new electrode for poly(pyrrole)-based rechargeable battery. J. Power Sources 1992, 40, 299-305.

5. Diaz, A.F.; Castillo, J.I.; Logan, T.A.; Lee, W.J. Electrochemistry of conducting polypyrrole films. J. Electroanal. Chem. 1981, 129, 115-132.

6. Pellagrino, J.; Radebaugh, R.; Mattes, B.R. Gas sorption in polyaniline. 1. Emeradline base. Macromolecules 1996, 29, 4985.

7. Selampinar, F.; Akbulut, U.; Ozden, M.Y.; Toppare, L. Immobilization of invertase in conducting polymer matrices. Biomaterials 1997, 92, 1163.

8. Kizilyar, N.; Akbulut, U.; Toppare, L.; Ozden, M. M.; Yagci, Y. Immoblization of invertase in conducting polypyrrole/polytetrahydrofuran graft polymer matrices. Synthet. Metal. 1999, 104, 45.

9. Ramelow, U.S.; Ma, J.; Darbeau, R. Electrical conductivities of polypyrrole reacted with dopant solutions. Mater. Res. Innov. 2001, 5, 40.

10. Ramelow, U.S.; Darbeau, R.; Ma, J.; Glenn, G.; Garrison, J. Effects of concentration and speciation of iron and solvent nucleophilicity/basicity on the electrical conductivty of polypyrrole: Introduction of a novel guage of polypyrrole conductivity. Mater. Res. Innov. 2004, 8, 29. 
11. Wang, H.L.; Toppare, L.; Ferandez, J.E. Conducting polymer blends: Polythiophene and polypyrrole blends with polystyrene and poly(bisphenol A carbonate). Macromolecules 1990, 23, 1053-1059.

12. Yurtsever, M.; Toppare, L. Theoretical investigation of block copolymerization of tetrahydrofuran and pyrrole. Polymer 1990, 40, 5459.

13. DePaoli, M.; Panero, S.; Prosperi, P.; Scrosanti, B. Study of electrochromism of polypyrrole/dodecyl sulfate in aqueous soluton. Electrochim. Acta 1990, 35, 1145.

14. Alkan, S.; Toppare, L.; Hepuzer, Y.; Yagci, Y. Block copolymers of thiophene-capped poly(methyl methacrylate) with pyrrole. J. Polym. Sci. Part A Polym. Chem. 1999, 37, 4218-4225.

15. Alkan, S.; Toppare, L.; Bakir, U.; Yagci, Y. Immobilization of urease in conducting thiophenecapped polymethylmethacrylate/pyrrole matrices. Synthet. Metal. 2001, 123, 95-99.

16. Sanchez, M.; Tompkins, J.; Rizk, W. Thermal Curing and Strength of PMMA Bone Cement. In Proceedings of ASME Summer Heat Transfer Conference, Las Vegas, NV, USA, July 2003.

17. Ramelow, U.; Braganza, S.; Darbeau, R.; Ramelow, G. Relaxation time, activation energy, and reaction pathway determination of polyethylene glycol/dimethacrylate-dopant $\left(\mathrm{I}_{2}\right)$ interaction with the nuclear magnetic resonance technique. J. Appl. Polym. Sci. 2006, 100, 5087-5101.

18. Ramelow, U.S.; Qui, G. Monomer reactivity ratios in UV-initiated free radical copolymerization reactions. J. Appl. Polym. Sci. 1995, 57, 911-920.

19. Stevens, M.P. Polymer Chemistry, An Introduction, 2nd ed.; Oxford University Press: Oxford, UK, 1990; p. 224.

20. Ebemele, R.O. Polymer Science and Technology; CRC Press: Boca Raton, FL, USA, 2000; pp. 215-216.

21. Billmeyer, F.W. Textbook of Polymer Science, 2nd ed.; John Wiley and Sons: New York, NY, USA, 1971; p. 330.

22. Ramelow, U.S.; Braganza, S.N.; Ramelow, G.J. Electrical conductivities of polyethylene glycol dimethacrylate reacted with iodine and lithium perchlorate dopants, and activation energy determination of polymer-dopant interaction. J. Appl. Polym. Sci. 2009, 112, 1916-1926.

(C) 2010 by the authors; licensee MDPI, Basel, Switzerland. This article is an open access article distributed under the terms and conditions of the Creative Commons Attribution license (http://creativecommons.org/licenses/by/3.0/). 